
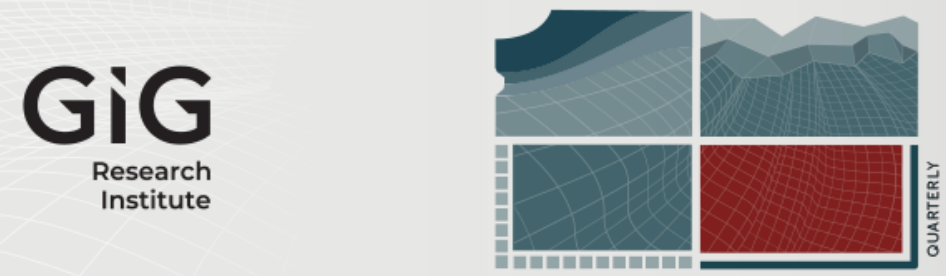

JOURNAL

OF

SUSTAINABLE

MINING

Volume 19 | Issue 1

Article 3

2020

\title{
Comments on "Life cycle assessment of cobalt extraction process" by Farjana et al. (2019)
}

Author(s) ORCID Identifier:

Rickard Arvidsson (iD 0000-0002-9258-0641

Mudit Chordia (iD) 0000-0002-9228-8579

Anders Nordelöf (iD) 0000-0002-7455-7341

Follow this and additional works at: https://jsm.gig.eu/journal-of-sustainable-mining

Part of the Explosives Engineering Commons, Oil, Gas, and Energy Commons, and the Sustainability

\section{Commons}

\section{Recommended Citation}

Arvidsson, Rickard; Chordia, Mudit; and Nordelöf, Anders (2020) "Comments on "Life cycle assessment of cobalt extraction process" by Farjana et al. (2019)," Journal of Sustainable Mining: Vol. 19 : Iss. 1 , Article 3.

Available at: https://doi.org/10.46873/2300-3960.1002

This Correspondence is brought to you for free and open access by Journal of Sustainable Mining. It has been accepted for inclusion in Journal of Sustainable Mining by an authorized editor of Journal of Sustainable Mining. 
Comments on "Life cycle assessment of cobalt extraction process" by Farjana et al. (2019)

\author{
Abstract \\ Keywords \\ Life cycle assessment; LCA; Cobalt \\ Creative Commons License \\ (c) (1)
}

Several points of critique are raised against the paper by Farjana et al. (J Sust Mining, 18(3): 150-161, 2019). The first regards the novelty of their paper. The second regards the age and quality of the main source data used. The third regards the description of the system boundary of their main data source.

This work is licensed under a Creative Commons Attribution 4.0 License. 


\title{
Comments on "Life cycle assessment of cobalt extraction process" by Farjana et al. [1]
}

\author{
Rickard Arvidsson*, Mudit Chordia, Anders Nordelöf
}

Environmental Systems Analysis, Department of Technology Management and Economics, Chalmers University of Technology, Vera Sandbergs Allé 8, 41296 Gothenburg, Sweden

T $\mathrm{n}$ the paper by Farjana et al. [1]: an environ1 mental life cycle assessment (LCA) of cobalt extraction is presented. The assessment is conducted with a cradle-to-gate system boundary and a functional unit of $1 \mathrm{~kg}$ cobalt extracted, thus including mining and purification steps until a relatively pure metal compound is reached. Naturally in such a study, the cobalt extraction is a key process for which relevant data of high quality should preferably be gathered. However, the authors obtain data for this process (presented in their Tables 3 and 4) from one single, previously conducted study: Nuss and Eckelman [2]. In fact, that study also assessed environmental and health impacts of cobalt extraction, specifically the impact categories cumulative energy demand, climate change, terrestrial acidification, freshwater eutrophication and human toxicity. Farjana et al. [1] write in their introduction that " $[t]$ o date, no research has reported the life cycle assessment of the cobalt extraction process and quantified the environmental effects on human health and ecosystems". However, that seems to be incorrect such an assessment has already been conducted by their main data source. The use of the same data for cobalt extraction makes the study by Farjana et al. [1] largely a repetition of that by Nuss and Eckelman [2]. This can be seen by comparing results for two impact categories included in both studies: cumulative energy demand and climate change. Based on a summing of the results in their Figure 5, the cumulative energy demand result in Farjana et al. [1] appears to be roughly $125 \mathrm{MJ} / \mathrm{kg}$ cobalt. The cumulative energy demand result in Nuss and Eckelman [2] is reported at $128 \mathrm{MJ} / \mathrm{kg}$ cobalt. The climate change impact for the base case in Farjana et al. [1] is reported at $11.7 \mathrm{~kg} \mathrm{CO} 2$ equivalents $/ \mathrm{kg}$ cobalt, whereas the climate change impacts in Nuss and Eckelman [2] is reported at $8.3 \mathrm{~kg} \mathrm{CO} \mathrm{CO}_{2}$ equivalents $/ \mathrm{kg}$ cobalt. The minor differences in results likely reflect some modifications in the modelling of electricity supply and some of the other inputs to the cobalt extraction, as well as minor differences in climate change impact assessment methods. We acknowledge that Farjana et al. [1] provided results for some additional impact categories compared to Nuss and Eckelman [2] (ozone depletion, particulate matter, ionizing radiation, photochemical ozone formation, terrestrial eutrophication, marine eutrophication, freshwater ecotoxicity, land use, water resource depletion and mineral depletion as well as weighted impacts). They also consider some additional scenarios for electricity supply, though only from different fossil resources (natural gas, lignite and oil). However, it remains questionable to claim that there has been no "life cycle assessment of the cobalt extraction process" which has "quantified the environmental effects on human health and ecosystems" prior to Farjana et al. [1] - the study by Nuss and Eckelman [2] clearly qualifies to that description. Farjana

Received 11 December 2019; accepted 24 December 2019.

Available online 5 October 2020

* Corresponding author.

E-mail address: rickard.arvidsson@chalmers.se (R. Arvidsson). 
et al. [1] thus give an exaggerated impression of the novelty of their study.

Furthermore, it should be noted that the data used by Farjana et al. [1] is relatively old and of highly questionable quality for assessing the impacts cobalt extraction on a detailed level. Although the authors do not state the temporal scope of their study explicitly, it seems their goal is to provide results reflecting current extraction procedures. For example, when they discuss global producers of cobalt in their Section 3, they refer to the relatively recent year 2017. However, the study by Nuss and Eckelman [2]; from which they derived their cobalt extraction data, is already five years old. In addition, Nuss and Eckelman [2] write in their supporting information that the source of their data is the Ecoinvent database version 2.2, released in 2010, specifically the dataset "cobalt, at plant, GLO" (for a licence fee, this database can be accessed from: https://www.ecoinvent.org/login-databases.html).

Studying the specific cobalt dataset in that database reveals that the time stamp for this dataset is year 2000 , making it almost 20 years old. Whether or not the data reflects the status of current cobalt extraction - or that of 2017 - thus remains uncertain. Moreover, when studying the dataset documentation, the following technology description is provided: "Data approximated with data from nickel mining and beneficiation. For the further treatment the process "reduction of oxides" is approximated by stoechiometric (sic) calculation - assuming a yield of $95 \%$ - and approximations for energy consumption from other chemical plants. No emissions are assumed for this treatment process." This means that the data does not even reflect actual cobalt extraction but has been approximated based on the extraction of nickel and stoichiometric calculations in lack of more specific data. This makes it even uncertain whether that dataset represents cobalt extraction as it was in the year 2000. Figure 1 in this comment provides a timeline of the chain of referencing for the cobalt extraction data applied by Farjana et al. [1].
There is a clear merit that LCA analysts gather data for key processes in a product system themselves, on-site or by consulting literature describing the procedures on a sufficiently detailed level. Thereby, it can be ensured that the study is unique and does not merely repeat previously conducted research. In addition, they can then assure that the data fits the goal of the study, e.g. in terms of temporal scope and quality. The developers of the Ecoinvent database write that it is common practice in LCA to focus data gathering efforts on selected key processes (often referred to as the foreground system), whereas data from databases, including their own, is suitable for modelling generic inputs, such as the production of electricity and base chemicals (often referred to as the background system) [3]. Nuss and Eckelman [2] might be forgiven for turning to the Ecoinvent database for cobalt extraction data, since they assessed environmental impacts of as many as 63 metals in their study. Naturally, such an extensive study needs to rely on previously derived data. Also, it can be argued that data from databases can be applied as best available approximation in assessments of products containing only a small share of cobalt. But for a study entirely dedicated to cobalt, such as Farjana et al. [1]; we find no excuses for relying on almost 20 years old, approximate data. Considering the old age and questionable quality of the available LCA data for cobalt extraction, providing more accurate and up-to-date data would truly be an important scientific contribution. We recommend a thorough data gathering effort for cobalt extraction, for example by site-specific investigations of extraction practices or at least by consulting the most recent technical literature on cobalt extraction. Here, the paper by Farjana et al. [1] constitutes a missed opportunity.

A final point of critique can be raised: Farjana et al. [1] write in their Section 4.2 that in their cobalt extraction data, "[a]ll of the production stages are considered from metal extraction, processing, delivery as a final product, waste emissions, recycling

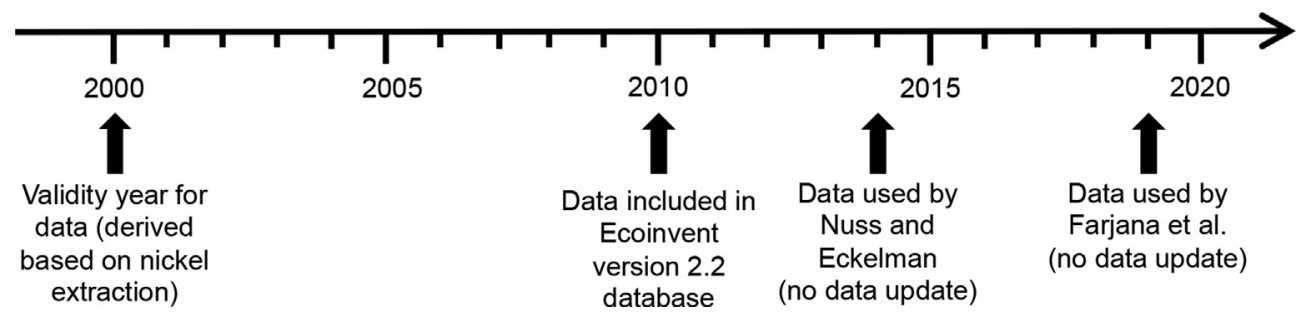

Fig. 1. Timeline showing the chain of referencing for the cobalt extraction data applied by Farjana et al. [1]. 
and end of life emissions". However, they also state that the study is a cradle-to-gate study, which by definition does not include the use and end-of-life phases [4], and consequently not, for example, "recycling and end of life emissions". When consulting the Ecoinvent version 2.2 data source regarding included processes, it says: "Raw materials, land-use, auxiliaries (sic) and energy consumption as well as emissions to air and water for extraction step. Auxillaries (sic) and energy consumption estimated for further treatment step. No emissions for further treatment taken into account. Overburden and tailing material from process together with losses of product not taken into account." There is thus no record of any delivery as a final product, recycling or end-of-life emissions. Nuss and Eckelman [2]; the data source cited by Farjana et al. [1]; do not mention any delivery as a final product, recycling or end-of-life emissions either. It thus appears there is also an erroneous description of the system boundary of the most important dataset in the paper by Farjana et al. [1].

\section{Ethical statement}

Authors state that the research was conducted according to ethical standards.

\section{Funding body}

The financial support from the Swedish research council Formas is gratefully acknowledged.

\section{References}

[1] Farjana SH, Huda N, Mahmud MAP. Life cycle assessment of cobalt extraction process. J Sustain Min 2019;18:150-61. https://doi.org/10.1016/j.jsm.2019.03.002.

[2] Nuss P, Eckelman MJ. Life cycle assessment of metals: a scientific Synthesis. PloS One 2014;9:e101298. https://doi.org/ 10.1371/journal.pone.0101298.

[3] Wernet G, Bauer C, Steubing B, Reinhard J, Moreno-Ruiz E, Weidema $B$. The ecoinvent database version 3 (part I): overview and methodology. Int J Life Cycle Assess 2016;21: 1218-30. https://doi.org/10.1007/s11367-016-1087-8.

[4] Baumann H, Tillman A-M. The Hitchhiker's Guide to LCA: an Orientation in Life Cycle Assessment Methodology and Application. Lund, Sweden: Studentlitteratur; 2004. 